\title{
Efficient Mucosal Immunization by Mucoadhesive and pH-Sensitive Polymeric Vaccine Delivery System
}

\author{
Lei Xing ${ }^{\dagger, 1,2,3,4}$ \\ Tian-Jiao Zhou ${ }^{\dagger, 1}$ \\ Ya-Tong Fan $^{1}$ \\ Yu-jing $\mathrm{He}^{1}$ \\ Tao Pang 1,3 \\ Ki-Hyun $\mathrm{Cho}^{5}$ \\ Jin-Jian $\mathrm{Lu}^{6}$ \\ Hu-Lin Jiang, ${ }^{* 1,2,3,4}$ \\ Chong-Su Cho ${ }^{*, 7}$
}

\author{
${ }^{1}$ State Key Laboratory of Natural Medicines, Department of Pharmaceutics, China Pharmaceutical \\ University, Nanjing 210009, P. R. China \\ ${ }^{2}$ Jiangsu Key Laboratory of Druggability of Biopharmaceuticals, China Pharmaceutical University, \\ Nanjing 210009, P. R. China \\ ${ }^{3}$ Jiangsu Key Laboratory of Drug Screening, China Pharmaceutical University, Nanjing 210009, P. R. China \\ ${ }^{4}$ Jiangsu Key Laboratory of Drug Discovery for Metabolic Diseases, China Pharmaceutical University, \\ Nanjing 210009, P. R. China \\ ${ }^{5}$ Department of Plastic Surgery, Cleveland Clinic, Cleveland, Ohio 44195, USA \\ ${ }^{6}$ State Key Laboratory of Quality Research in Chinese Medicine, Institute of Chinese Medical Sciences, \\ University of Macau, Macao, P. R. China \\ ${ }^{7}$ Department of Agricultural Biotechnology and Research Institute for Agriculture and Life Sciences, \\ Seoul National University, Seoul 08826, Korea
}

Received May 29, 2018 / Revised July 4, 2018 / Accepted September 3, 2018

\begin{abstract}
Mucosal surfaces as the largest immune organ of human body cover $400 \mathrm{~m}^{2}$ of the body including the gastrointestinal, urogenital, and respiratory tracts. The local mucosal immunity is an important first line of defense against many pathogens because most pathogens initiate their infection through access to the mucosal region of body. Also, the mucosal vaccines induce mucosal and systemic immunity simultaneously. Therefore, attracted by the advantages of mucosal immunity, researchers keep an eye on the mucoadhesive and $\mathrm{pH}$-sensitive polymeric vaccine delivery system to solve several limitations of mucosal administration, making mucosal immu-

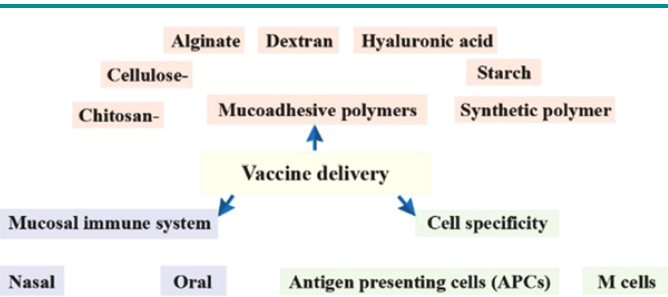
nity receive great interests lately. In this review, we discuss natural polymer- and synthetic polymer-based mucoadhesive and pHsensitive systems used for mucosal vaccine delivery. Also, we cover how to target antigen presenting cells and M cells for the cell specificity. Finally, we conclude the significant progress in mucosal vaccine and the prospect mucosal vaccine research in the future.
\end{abstract}

Keywords: mucosal immunization, mucoadhesive polymer, $\mathrm{pH}$-sensitive, vaccine delivery, $\mathrm{M}$ cell targeting.

\section{Introduction}

The immune system is one of host defense systems that contain many biological structures and processes in disease-preventing organisms. In order to function the immune system properly, it must detect a variety of agents known as pathogens. If pathogens undermine these disorders, the innate immune system provides an immediate rather than non-specific response

Acknowledgments: We thank the National Natural Science Foundation of China (81773667 and 81573369), and the Natural Science Foundation of Jiangsu Province (BK20140659). This work was also supported by the Project Program of State Key Laboratory of Natural Medicines, China Pharmaceutical University (SKLNMZZJQ201601), the "111" Project from the Ministry of Education of China and the State Administration of Foreign Experts Affairs of China (B16046). This workwasalso supported by the Outstanding Youth Fund of Jiangsu Province of China (BK20160031) and the Fundamental Research Funds for the Central Universities (2632018PT01 and 2632018ZD12). This research was also supported by Basic Science Research Program through the National Research Foundation of Korea (NRF) funded by the Ministry of Education (2016936920).

*Corresponding Authors: Hu-Lin Jiang (jianghulin3@163.com),

Chong-Su Cho (chocs@snu.ac.kr)

${ }^{\dagger}$ These authors contributed equally to this work. whereas the adaptive immune system can be activated when the pathogen successfully avoids the innate response. Here, the immune system adapts its response during pathogen infection to improve its identification of pathogens. This improved response can be then retained in the form of immune memory after the pathogens are eliminated, and allow the adaptive immune system to initiate faster and stronger attacks when the pathogens are encountered. Based on this, the vaccination came into being a reality because the vaccination is the administration of antigen to stimulate an individual's immune system for development of adaptive immunity to a pathogen. Also, the vaccination as the simple way to boost the immunity for fighting off the infections is a cost-effective and probably the best preventable strategy for most diseases such as hepatitis B and influenza. ${ }^{1}$ One of the most important vaccine strategies is antigen. Immunogenicity, antigenic determinant as an epitope, dose, and frequency of antigen treatment can also affect the efficacy of the vaccine. Furthermore, the host itself can affect the efficacy of the vaccine, such as innate immunity, $T$ and $B$ cells effector function and long-term memory effect. Besides, adjuvant, ${ }^{2}$ vaccine carrier $^{3}$ and immune route can impact the efficacy of vaccines.

Immune systems with immune surveillance, defense and 
regulatory role include systemic immune system (lymphoid, spleen etc.) and mucosal immune system [gut-associated lymphoid tissue (GALT) etc.]. Especially, the mucosal immune system as the largest part of the immune system contains approximately three-fourths of all lymphocytes and produces secreted IgA (SIgA) per day to protect mucosal surfaces from pathogens. ${ }^{5}$ Nowadays, much attention has been attracted by the mucosal immune system due to the easy administration, good patient's compliance and feasibility. On the other hand, the mucosal immune limitations such as low permeability, low stability and low efficiency need to be solved. Therefore, researches on mucosal immune vaccine carrier and adjuvant are increasingly focused.

It has been reported that systemic immunity by parenteral immunization only affects systemic infections although it cannot give mucosal surfaces. On the contrary, the mucosal vaccines can be used to induce systemic and mucosal immune responses by producing sIgA which cannot be obtained by systemic immunity. ${ }^{6}$ This mucosa-associated lymphoid tissue (MALT) is distributed on the mucosa of the respiratory tract, gastrointestinal tract, and urogenital tract, such as bronchus-associated lymphoid tissue (BALT), GALT, and nasal-associated lymphoid tissue (NALT) ${ }^{7.8}$ When the antigen is encountered, B cells are transformed into antibody-secreting plasma cells, producing antibodies to excrete pathogens to the mucosal surface as a mucosal reaction, while dendritic cells (DCs) are used by major antigen-tissue compatibility complexes (MHC) classes I and II molecules to $\mathrm{CD} 8^{+}$and $\mathrm{CD} 4^{+} \mathrm{T}$ cells. The activation pathway of $\mathrm{CD}^{+} \mathrm{T}$ cells and $\mathrm{CD} 4^{+} \mathrm{Th} 1$ cells produces cytotoxic $\mathrm{T}$ lymphocytes (CTL) that activate macrophages to kill the intracellular pathogen or the infected person for cell response, while the $\mathrm{CD} 4^{+} \mathrm{Th} 2$ cell activation pathway produces activated B lymphocytes, neutralizing the extracellular pathogens as humoral responses $^{3,9}$ as shown in Figure 1.

This review is composed of three parts. In the first part, we

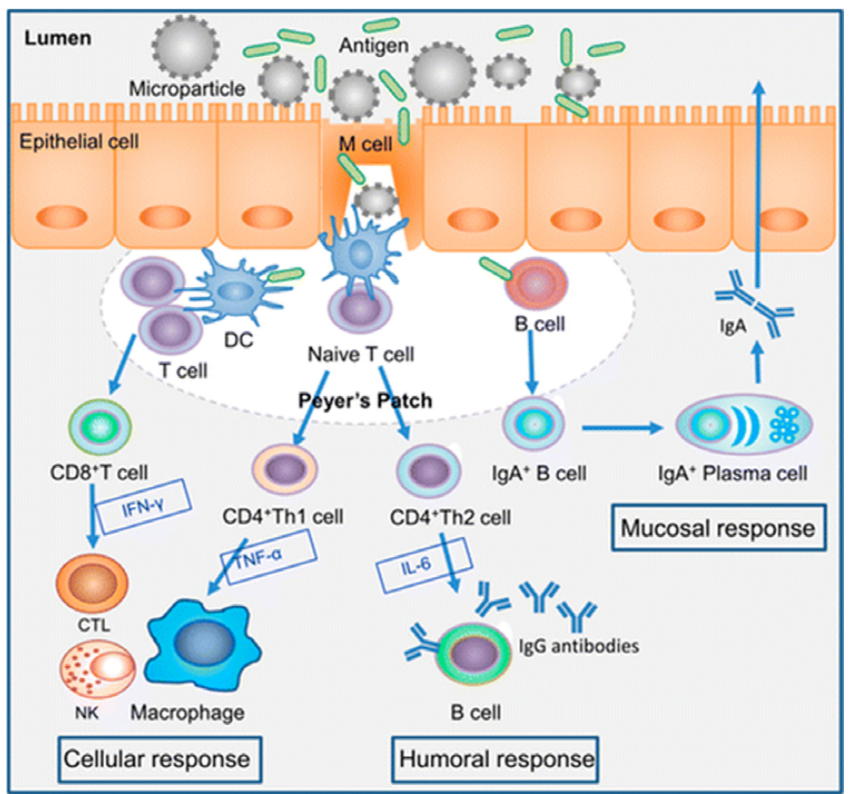

Figure 1. Schematic diagram of various immune responses induced by particulate vaccine system. ${ }^{9}$ Copyright 2015 , with permission from American Chemical Society. introduce typical routes of mucosal immunization, especially the characteristics of nasal and oral vaccination, the most common mucosal immunity. In the second part, we provide a broad overview of natural polymer- and synthetic polymer-based systems used for vaccine delivery. In the third part, for targeting vaccine delivery, we cover recent studies of vaccine delivery that have applied to target antigen presenting cells (APC) and $M$ cells to get cell specificity. Finally, we conclude the significant progress in mucosal vaccine and prospect the mucosal vaccine researches in the future.

\section{Mucosal Immune System}

Mucosal surfaces are the main entry points for many pathogens, and mucosal immune activity plays a key role in protecting these surfaces from foreign invasion. The mucosal immune system is consisted of tissues, lymphocytes and constituent cells, as well as effector molecules such as antibodies, cytokines and chemokines. These factors react to pathogens (or mucous membrane vaccines) by stimulating the complex coordination of innate and adaptive immune responses that confer protection on cellular processes ${ }^{10}$ as shown in Figure 2. The mucosal vaccination as an alternative strategy to parenteral administration, has been explored to more efficiently induce mucosal and systemic immune responses. Development of the mucosal antigens delivery system is a powerful challenge.

\subsection{Routes of mucosal immune system}

Delivering antigens to specific target sites using polymers can

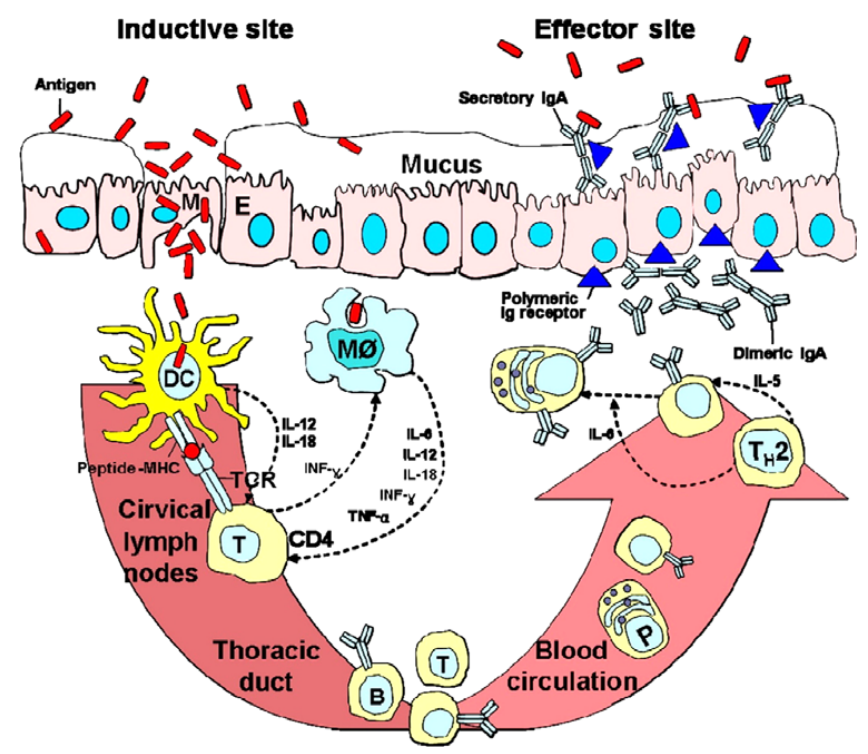

Figure 2. The common mucosal immune system (CMIS). The CMIS connects inductive sites with effector sites such as the lamina propria of the respiratory and intestinal tracts, and glandular tissues for the generation of antigen-specific IgA responses, and helper T cell 1 (Th1)and cytotoxic T lymphocyte (CTL)-dependent immune responses, which function as the first line of defense at mucosal surfaces. M: microfold cell; E: epithelial cell; MØ: macrophage; DC: dendritic cell; T: T lymphocyte; B: B lymphocyte; P: plasma cell; TCR: T cell receptor; MHC: major histocompatibility complex and Th2: T helper cell $2 .{ }^{10}$ Copyright 2009, with permission from Elsevier. 


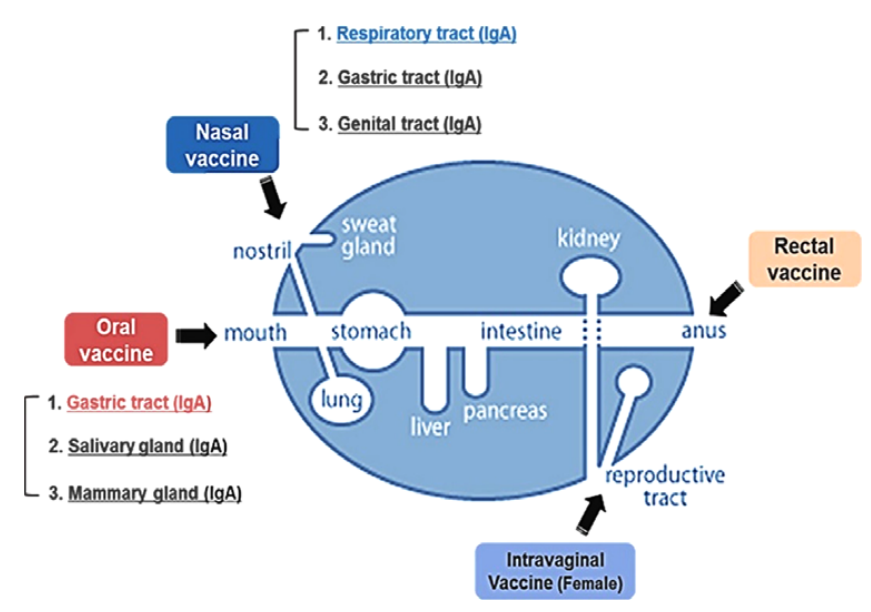

Figure 3. Schematic diagram of the mucous membranes of the body and typical immunization routes.

trigger different mucosal immunity. The routes of vaccination for arising mucosal immune system are nasal, oral, rectal and intravaginal routes as shown in Figure 3. Although mucosal vaccines can be delivered nasally, buccally, vaginally, rectally, conjunctivally, and transdermally, many investigators are actively pursuing vaccines that are specifically administered through the nasal and oral routes. ${ }^{10}$

\subsection{Nasal immunization}

\subsubsection{Advantages of nasal immunization}

The highly effective vaccine absorption of the nasal mucosa is due to the large surface area of the nasal epithelium. ${ }^{2}$ Therefore, the nasal administration of the vaccine can directly absorb the drug to avoid gastrointestinal damage. ${ }^{3}$ Also, the nose shows relatively low enzyme activity, which protects the vaccine against nasal enzymatic degradation and allows usage of smaller doses. ${ }^{4}$ The dose of antigen delivered via the nasal cavity is demonstrated to be 4-fold lower than that of oral vaccine and still induces strong antigen-specific antibody responses in serum and vaginal secretions. ${ }^{5}$ The nasal vaccine not only induces a systemic IgG antibody response, but also induces a mucosal IgA antibody response, resulting in a two-layer immune defense of the infectious disease. Furthermore, the nasally delivered vaccines are equally effective in inducing antigen-specific immune responses within the mucosa and system. ${ }^{6}$ In addition, due to the free administration of needles and syringes, there is no doubt that nasal vaccines are patient-friendly and convenient.

\subsubsection{Disadvantages of nasal immunization}

Despite the many advantages of nasal vaccines, there are some limitations that prevent these researches from successfully developing new nasal vaccines. One of the most important limitations of nasal immunity is the general rapid elimination of vaccine formulations on mucosal surfaces due to mucociliary clearance although vaccines do not readily penetrate the nasal membranes. Substances administered through the nasal cavity are cleared from the nasal membranes by mucociliary clearance within $21 \mathrm{~min}$, whereas the normal clearance time for
Table 1. Characteristics of nasal vaccination

\begin{tabular}{cc}
\hline Advantages & Disadvantages \\
\hline Easily accessible & \\
Highly vascularized & Mucociliary clearence \\
Numerous microvilli & \\
Porous endothelial membrane & \\
Easy immunization of large & \\
population groups & \\
Cross-protective immunity & Degradation of vaccine by enzymes \\
Needles and syringes free & \\
Low-cost & \\
Patient friendly
\end{tabular}

human nasal mucosa is reported as 12 to $15 \mathrm{~min}^{11}$

Another critical limitation of nasal vaccines is the enzyme barrier that hinders drug absorption and penetration. This is due to various foreign metabolic enzymes, including the cytochrome P-450 enzyme as an oxidized I-phase enzyme, the IIphase enzyme as a non-oxidase and proteolytic enzyme. ${ }^{12}$ It has been reported that the proteolytic enzymes in the nasal mucosa reduce the nasal absorption of peptide drugs. ${ }^{12}$ Thus, therapeutic vaccines delivered intranasally are often limited by the systematic elimination of enzymatic degradation. The characteristics of nasal vaccination are shown in Table 1.

\subsection{Oral immunization}

\subsubsection{Advantages of oral immunization}

Recently, researches have been primarily focused on preparation of nanoparticles (NPs) in oral immunization for improved mucoadhesion, enhanced permeation, drug retention capabilities and sustained release of drugs. ${ }^{13}$ Oral vaccinations have the ability to improve biodistribution compared to traditional injections because they are easy to administer and allow self-administration of oral formulations, ${ }^{14}$ which can further reduce cost of vaccine programs. In addition, needle-free administration would eliminate occupational needle-stick injuries. From a regulatory point of view, oral vaccines allow for more cost-effective production because they do not require extensive purification required for injectables.

Oral immunization is likely to increase vaccine efficacy simply by increasing accessibility and coverage. Also, the oral route also provides the additional benefit of stimulating mucosal immunity. Mucosal epithelium covers the largest surface area in the body and constitutes the first line of defense against outside pathogens. ${ }^{15,16}$ These mucosal surfaces involve the coordination of physicochemical and biological barriers to regulate the ingress of nutrients and the reaction to foreign bodies. Prophylactic vaccination at the site of infection can help prevent infectious diseases ${ }^{17}$ although the same defense mechanisms used to exclude pathogens must also be circumvented to develop effective oral vaccines.

\subsubsection{Disadvantages of oral immunization}

To promote a robust immune response, oral delivery of anti- 
Table 2. Characteristics of oral vaccination

\begin{tabular}{cc}
\hline Advantages of oral vaccine & Disadvantages of oral vaccine \\
\hline Easy to administer & \\
Allow self-administration & Gastrointestinal tract barrier \\
Low-cost & Extremely acidic pH \\
Improved distribution & \\
Needle-free administration & Limited absorption time \\
Cost-effective & \\
High vaccine efficacy & \\
High accessibility and coverage &
\end{tabular}

gens requires overcoming several physicochemical and biological barriers in the gastrointestinal tract. They include the biological barrier of the intestinal epithelium and its mucus-secreting layer, which digests and consumes substances that absorb nutrients and protects the body from the threat of disease. The gastrointestinal tract includes a highly acidic environment in the stomach, a significant $\mathrm{pH}$ range along the length of the gastrointestinal tract, and the presence of proteolytic enzymes responsible for protein degradation. These properties interfere with the delivery of fragile biological molecules such as antigenic proteins or polypeptides that are highly susceptible to degradation and denaturation. ${ }^{18}$ In addition, the absorption of these preparations has a time limit due to the residence time in the small intestine (3-4 h) during most of the absorption process. ${ }^{19}$ The characteristics of oral vaccinization is shown in Table 2.

\section{Mucoadhesive Polymers}

\subsection{Importance of mucoadhesive polymer}

A major problem with mucosal drug delivery is the rapid clearance of the administered drugs due to short contact with the mucus layer. In order to reach the site of action, the drug must enter the internal site (eg: mucosal lymphoid tissue of the blood vessels and antigens of the drug) from an external location as a mucosal barrier. ${ }^{13}$ Unfortunately, the drug is cleared from the mucus layer before crossing the external site. In oral administration, most drugs are associated with chyme, and then pass directly through the gastrointestinal tract within 3-4 hours and are eliminated in the stool. ${ }^{20}$ For nasal and pulmonary administration, the captured materials in the mucus are cleared by the cilia as a mucociliary clearance, and the intraluminal gel layer of mucus changes every 10 to $20 \mathrm{~min}$, both of which result in efficient clearance of the particles. ${ }^{21}$ Because of the generally accepted view that the longer a drug stays in the mucosa, the higher the drug absorption efficiency, an adherent polymeric carrier has drawn much attention in drug delivery over the past 40 years. The $\mathrm{pH}$ at the bioadhesion to substrate interface can influence the adhesion of bioadhesive polymers possessing ionizable groups. Many bioadhesive polymers used in drug delivery are polyanions possessing carboxylic acids. If the local $\mathrm{pH}$ is above the $\mathrm{pK}$ of the polymer, it will be mostly ionized; if the $\mathrm{pH}$ is below the $\mathrm{pK}$ of the polymer, it will be mostly unionized. ${ }^{22}$ The $\mathrm{pH}$-sensitive polymers are commonly used in oral delivery systems to target different $\mathrm{pH}$ ranges of the digestive tract because the $\mathrm{pH}$ in the stomach ranges from 1 to 2.5 and
6.4 to 7.5 in the intestine. ${ }^{23}$

In general, polymer mucoadhesion has been reported to adhere to mucus by the interaction between mucin surfaces and synthetic or natural polymers. ${ }^{24-28}$ Mucoadhesive polymers include chitosan, sodium alginate, cellulose derivatives, dextran, hyaluronic acid, starch, and Eudragit. Mucosal attachment of a drug carrier provides several advantages, such as targeting the drug to the mucosal surface: (i) Increasing the bioavailability of the drug by increasing the residence time in the mucosa, (ii) controlled release through mucosal channels to reduce the frequency of dosing required, (iii) reduction of dose-related side effects by improving the therapeutic profile of the drug, (iv) reduced costs, ( $v$ ) specificity for a particular tissue site by the mucosal location of the drug, and (vi) patient compliance as compared to parental injections. For clinical use of mucoadhesive drug carriers, the mucoadhesive properties must be taken into account as well as other desired characteristics such as non-toxicity, degradability, rapid adherence to most tissues, low irritation, ease of incorporation into the drug, low cost and high stability delivery system. ${ }^{29}$ In order to take advantages of mucosal adhesion to the fullest, based on the knowledge of the mucoadhesive mechanism, a number of module-based mucoadhesive polymers have been developed to provide enhanced mucoadhesive properties.

\subsection{Natural polymers}

Because mucosal-delivered antigens via nasal and oral routes are taken up by epithelial microfold cells (M cells) in Peyer's patches (PP), especially abundant in the ileum of small intestine, ${ }^{30}$ several barriers such as gastric $\mathrm{pH}$, enzymatic degradation and rapid transit should be overcome. To solve the abovementioned problems, researchers have attracted the interest in $\mathrm{pH}$-sensitive and mucoadhesive natural polymeric carriers to improve immune response of mucosal vaccine delivery.

\subsubsection{Chitosan-based system}

Chitin, poly $[\beta-(1-4)-N$-acetyl-D-glucosamine], identified in 1884 , as a natural polysaccharide is second most important natural polymer in the world. ${ }^{31}$ Chitosan obtained by deacetylation of chitin has been broadly used for the pharmaceutical applications due to its excellent properties, such as nontoxic, biocompatible, muco-adhesive properties and so on. These excellent properties make it being one of the best choices for vaccine delivery. The chitosan has mucoadhesive properties on its own although the solubility at a physiological $\mathrm{pH}$ can cause pre-systemic metabolism of drugs when faced with proteolytic enzymes, making it a poor material for particles designed to circulate in the body. For the purpose of improving this limitation, several chemical modifications have been made as shown in Figure 4.

Polymeric nanoparticles possess several significant advantages such as 1) high solubility result in significant size reduction, 2) encapsulation of drug to improve drug stability, 3) various choice in the route of administration,4) targeted ability by modification, and 5) reduction of side-effect over another approaches. ${ }^{32}$ Also, the polymeric nanoparticles play a more and more significant role in the design and development of vaccines because the 
<smiles>COC1CC(NC(=O)C(N)CS)C(C)OCC1CO</smiles>

Chitosan-cysteine<smiles>COC(CO)CC(NC(=O)[GeH2][SiH3])C(C)OC</smiles>

Chitosan-glutathione<smiles>COC1CC(C)OC(C)C(NC(=N)CCCS)C1</smiles>

Chitosan-4-thio-butylamidine<smiles>COCC(CO)CC(NC(=O)c1ccccc1)OC(C)C</smiles><smiles>COC1CC(NC(=O)CS)C(C)OC1CO</smiles>

Chitosan-thiooglycolicacid<smiles>COC1CC(NC(=O)C(CS)NC(C)=O)C(C)OC1CO</smiles>

Chitosan-6-mercaptonicotinic acid

Chitosan-N-acetylcysteine

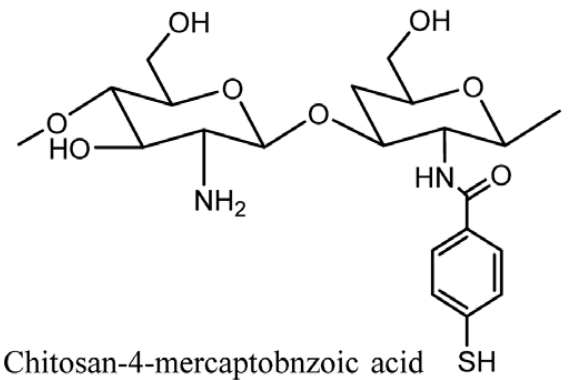<smiles>COC1CC(NC(=O)C(NC(C)=O)C(C)(C)S)C(C)OCC1CO</smiles>

Chitosan-N-acetylpenicilamine

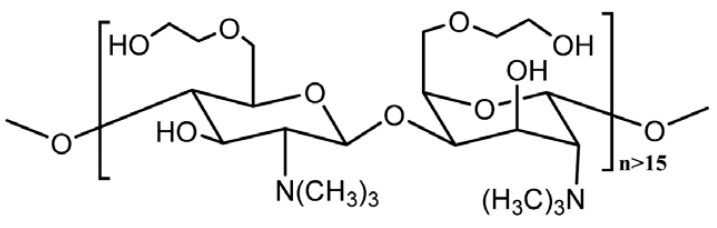

Methylglycol chitosan

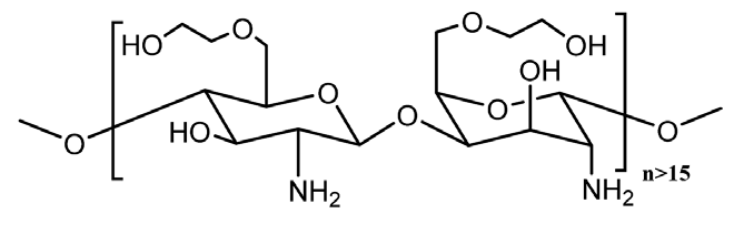

Glycol chitosan

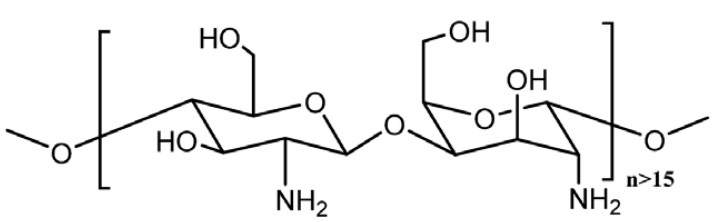

Deacytelated chitosan

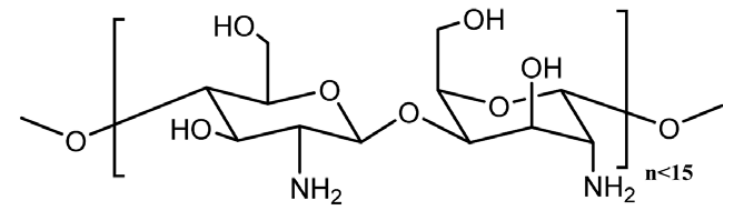

Chitosan oligosaccharide

Figure 4. Chemical structures of the presented chemical-modified mucoadhesive chitosan variants.

vaccine-loaded polymeric nanoparticles show improved safety and efficacy over conventional formulations. ${ }^{33}$ Farhadian et $a l^{34}$ used trimethyl chitosan (TMC), a quaternary derivative of chitosan, to develop HBsAg-loaded $\mathrm{pH}$-sensitive and mucoadhesive TMC/hydroxypropyl methyl cellulose phthalate (HPMCP) nanoparticles. It was a favorable delivery vehicle that could not only load but also preserve HBsAg from degradation and this delivery system could be used as a substitute for vaccine delivery and adjuvant to the conventional parental dosage form as an oral administration. Sublingual (SL) vaccination without safety risks associated with an intranasal route or the complications of oral vaccination, is an attractive administration due to the outstanding properties of painless, relatively simple and needle-free. Justin et al. showed that methyl glycol chitosan (MGC) and/or CRX-601 as an immune response enhancer by effectively triggering toll-like receptor 4 (TLR4), had the ability of adjuvanting split-flu vaccines administered (SL) to trigger a stronger mucosal vaccination and at least an equivalent sys- 
temic immune response to flu vaccine delivered intramuscularly (IM). ${ }^{35}$ Using adjuvants that are safe and efficient such as MGC and/or CRX-601 to stimulate equivalent or better immune responses under SL vaccination will be an appealing SL vaccination strategy for future vaccine development.

The nanoparticles may not be able to meet the demand of vaccine delivery. Therefore, researchers have developed microparticle delivery system. Chitosan microspheres (CMs) can be easily prepared by an ionic gelation process with a different salt solution according to various purposes. ${ }^{36,37}$ Jiang et al. prepared mannosylated chitosan microspheres (MCMs) as a vaccine delivery platform, which loaded bordetella bronchiseptica antigens containing dermonecrotoxin (BBD).$^{38}$ In vivo experiments revealed that BBD-MCMs rather than BBD-loaded CMs induced much better BBD-specific IgA antibody responses in saliva and serum, implying mannose moieties has significant impact in activating immune-stimulating through a specific interaction between mannose groups and its receptors. Bucarey et al. established an experimental oral vaccine originated from combining two strategic approaches against porcine circovirus type 2 (PCV2)-associated diseases. The vaccine delivery system based on yeast-derived PCV2 virus-like particles (VLPs)-loaded chitosan microparticles showed an antigen-specific cellular immune response after oral administration, indication of a safe, simple oral vaccines system..$^{39}$ Kaur et al. prepared CMs conjugated with wheat germ agglutinin (WGA) and loaded reduced brominated derivative of noscapine (Red-Br-Nos) for increasing anti-inflammatory. ${ }^{40}$ The results demonstrated that WGAconjugated CMs loaded with Red-Br-Nos had surface bioadhesive property and promoted affinity toward colon mucin cells. Also, the WGA-conjugated CMs loaded with Red-Br-Nos remarkably weakened the dextran sodium sulfate (DSS)-encouraged neutrophil infiltration and pro-inflammatory cytokine production in DSS-induced colitis model mice. ${ }^{41}$ Zheng et al. designed novel composite microspheres of alginate-chitosan-poly(lacticco-glycolic acid) of hepatitis B surface antigen (HBsAg) as single-injection vaccines. Compared with double injections of HBsAg-aluminum vaccine and a single dose of PLGA microspheres of HBsAg, the composite microspheres improved entrapment efficiency of the conventional HBsAg-PLGA microspheres and maintained the higher antibody levels. This system holds a strong promise for improving PLGA-based protein delivery and achieving single-shot vaccination. ${ }^{42}$ For mucosal vaccine, instability and poor absorption of antigens in the gastrointestinal tract is a major handicap in the development of oral antigen delivery system. Biocompatible and biodegradable chitosan is a mucoadhesive polymer with absorption-enhancing property to improve the immunogenicity of intranasal antigen delivery systems. ${ }^{43}$ Li et al. developed a novel oral antigen carrier based on alginate-coated chitosan microparticles with a mean diameter of about $1 \mu \mathrm{m}$ to meet the requirement of mucosal vaccine. ${ }^{44}$ This delivery system showed lower initial burst release of BSA and property of protecting BSA from degradation or hydrolysis in acidic condition, indicating that alginate-coated chitosan microparticles might be an effective vehicle for administration of antigens via oral route.

DNA vaccine known as nucleic acid vaccine or gene vaccine is a eukaryotic expression plasmid DNA (or RNA) that encodes the immunogen or something associated with the immunogenicity. It can enter animal body and uptake by host cells, and then it express antigen protein to stimulate the body to produce non-specific and specific immune response. The protein encoded by DNA vaccine is similar to the antigen expressed after viral infection, and it has also advantages in the safety of live attenuated vaccine and further improvement of immune system activation. Zhao et al $^{45}$ successfully prepared Newcastle disease virus DNA (NDV) vaccine system through encapsulating NDV into chitosan nanoparticles (NDV-CS-NPs), which protected the plasmid DNA from degradation and helped its expression. They also induced significantly higher mucosal and humoral immune responses, suggesting that the DNA vaccine-loaded chitosan nanoparticle is a safe and efficient drug release carrier system. $\mathrm{Xu}$ et al $^{46}$ prepared chitosan-DNA vaccine complexes to stimulate CVB3 specific immune responses. The results demonstrated that immunization with chitosan-DNA encoding VP1 (chitosanpcDNA3-VP1) on mice via intranasal administration produced much higher levels of mucosal secretory IgA and serum IgG compared with groups without chitosan (Figure 5). Zhou et $a l^{47}$ used chitosan effectively to deliver HBV DNA vaccine into APCs. More concretely, they entrapped PEI/DNA complexes in MC microspheres. Compared with naked DNA, HBV DNA-loaded MC microspheres enhanced antibody responses at all doses and time points and shortened the time required for detectable antibody responses. Similarly, Heuking et al ${ }^{48}$ modified Toll-like receptor (TLR-7) agonistic moiety to chitosan by PEG linker. This system significantly increased the ability of interleukin-8related immune stimulatory in human THP-1 macrophages compared with controls.

\subsubsection{Cellulose-based system}

The cellulose as a typical polysaccharide composed of the repeated connection of D-glucose units, is the most important inexhaustible polymeric raw material with good biocompatibility, hydrophilicity, biodegradability, chirality and easy modification capacity. ${ }^{49}$

Cellulose derivatives, such as hydroxyethyl cellulose (HEC), hydroxypropyl cellulose (HPC), hydroxypropylmethyl cellulose (HPMC), carboxymethyl cellulose (CMC), cellulose acetate phthalate (CAP) and hydroxypropyl methycellulose phthalate (HPMCP), are recognized as the popular polymeric materials routinely used in medical and pharmaceutical applications, such as vaccine delivery system..$^{50}$

Due to the acidic-resistant property of some cellulose derivatives, Maharaj et al. encapsulated viral antigens, concanavalin A and other proteins with cellulose acetate phthalate (CAP) having a $\mathrm{pH}$-sensitivity. ${ }^{51}$ An oral enteric-coated killed virus vaccine has been shown successfully to be superior for providing immunological protection with CAP, improved convenience and less toxicity in humans. ${ }^{52}$ Lin et al. also prepared enteric-coated microspheres of Mycoplasma hyopneumoniae vaccine (MHV) with $\mathrm{CAP}^{53,54}$ The MHV-loaded CAP microspheres were not only thermally more stable than the unencapsulated MHV, but also exhibited an excellent enteric function to prevent $\mathrm{pH}-$ related inactivation. Therefore, the MHV-loaded CAP microspheres could 
be mixed with pig feed for oral administration to protect the vaccine from the destructive action of the enzymes or the low $\mathrm{pH}$ environment of the stomach.

Cellulose-based nanoparticles were also prepared from oppositely charged carboxymethyl cellulose (CMC) and quaternized cellulose (QC) through the electrostatic interaction. The efficient transfection efficiency and low toxicity of the CMC-QC nanoparticles made suitable candidates for DNA vaccine delivery because the DNA vaccine was developed for preventing infection with bovine viral diarrhea virus (BVDV), pMASIA-tPAstE2.2. ${ }^{55}$ The microcrystalline cellulose (MCC) had been used as a carrier to develop a novel recombinant protein conjugate for oral vaccine delivery system, which is consisted of a combination of recombinant antigens, adjuvants, and targeting agents for the inductive sites of the mucosal immune system. ${ }^{56}$ The protein stayed bound to MCC in simulated gastric fluid ( $\mathrm{pH} 1.2$ ) and was released in phosphate buffered saline ( $\mathrm{pH}$ 7.4). In addition, the affinity test of the protein to MCC in bile salt solution or fed simulated small intestinal fluid ( $\mathrm{pH}$ 5.0) showed that the bile salts did not affect the affinity of the protein to MCC, indicating that the protein could be used as an oral H1N1 vaccine.

Magnetic particles consisted of sulfated cellulose had been developed for the specific binding of the antigen of interest (influenza A virus particles), followed by direct formulation and injection into mice for immunization. ${ }^{57}$ The immunized mice showed an efficient induction of anti-A/PR antibodies that conferred full protection against a lethal A/PR virus challenge. To overcome several barriers such as gastric $\mathrm{pH}$, enzymatic degradation and rapid transit to orally deliver antigens for taking up by epithelial microfold cells in Peyer's patches of small intestine, Lee et al. designed $\mathrm{pH}$-sensitive and mucoadhesive polymeric microparticles (MPs) prepared by double emulsion technique using thiolated cellulose acetate phthalate (T-CAP) to enhance immune response of foot-and-mouth disease (FMD) virus (FMDV) subunit vaccine as shown in Figure $5^{30}$ Thiolation of CAP improved the mucoadhesive property of CAP to prolong the MPs transit time through the gastrointestinal tract. Thiolated CAP (T-CAP) also slowed down antigen release in acidic $\mathrm{pH}$ of the stomach but released more antigens in neutral $\mathrm{pH}$ of the small intestine due to the $\mathrm{pH}$-sensitivity of the T-CAP. Therefore, oral immunization of a chimerical multi-epitope recombinant protein as the FMD subunit vaccine via T-CAP MPs effectively delivered the vaccine to Peyer's patches eliciting mucosal IgA response.

\subsubsection{Alginate}

Alginate is a mucoadhesive polymer consisting of 1,4 -linked $\beta$ D-mannuronic acid (M), $\alpha$-L-guluronic acid (G). The safety, nonimmunogenicity, biodegradability and biocompatibility of alginate make it a suitable candidate for mucosal antigen delivery. Tetanus toxoid (TT) loaded alginate microspheres were featured by preserved structural stability, low release rate and immunoreactivity of encapsulated antigen. ${ }^{58}$

\subsubsection{Dextran}

Dextran as a bioadhesive polymer decreased the mucociliary transport rate and prolonged the retention time of nasal cavity. In addition, cross-linked dextran (CDM) functionalized as absorption adjuvant was used to overcome the mucosal barriers and increase immune responses of Quillaja saponins (QS) through nasal immunization against tetanus toxoid. ${ }^{59}$

\subsubsection{Hyaluronic acid (HA)}

The HA is an acid mucopolysaccharide consisted of D-glucuronic and $\mathrm{N}$-acetyl-D-glucosamine. Hyaluronic acid is commonly found in the extracellular tissue matrix of vertebrates and has been shown to be bioadhesive both in vitro and in vivo. O'Hagan et al. applied mucocal delivery of HA derivatives, such as esterified HA and auto-crosslinked HA by a combination with antigens and adjuvants to enhance the immunogenicity of the antigens because the bioadhesive properties of HA decreased the mucociliary clearance rate from nasal cavity and allowed longer contact time between antigen and absorbing membrane. ${ }^{60}$ Fan et al. developed an intranasal vaccine platform based on cationic liposome- HA hybrid nanoparticle (NP) system. ${ }^{61}$ Incorporation of cationic liposomes with thiolated HA allowed for facile surface decoration of NPs with thiol-PEG, resulting in improving colloidal stability and prolonged circulation release.

\subsubsection{Starch}

Starch is one of polycarbohydrates consisted of glucose units and connected by glycosidic bonds. ${ }^{62}$ Due to its biocompatibility, biodegradability and swellability, starch-based carriers are of interest for oral, nasal and intramuscular drug delivery. ${ }^{63-65}$ For example, poly(acrylic starch) microspheres (PAS) were prepared as rotavirus vaccine delivery system. ${ }^{66}$ The PAS was degraded enzymatically and had a fast antigen release rate, and

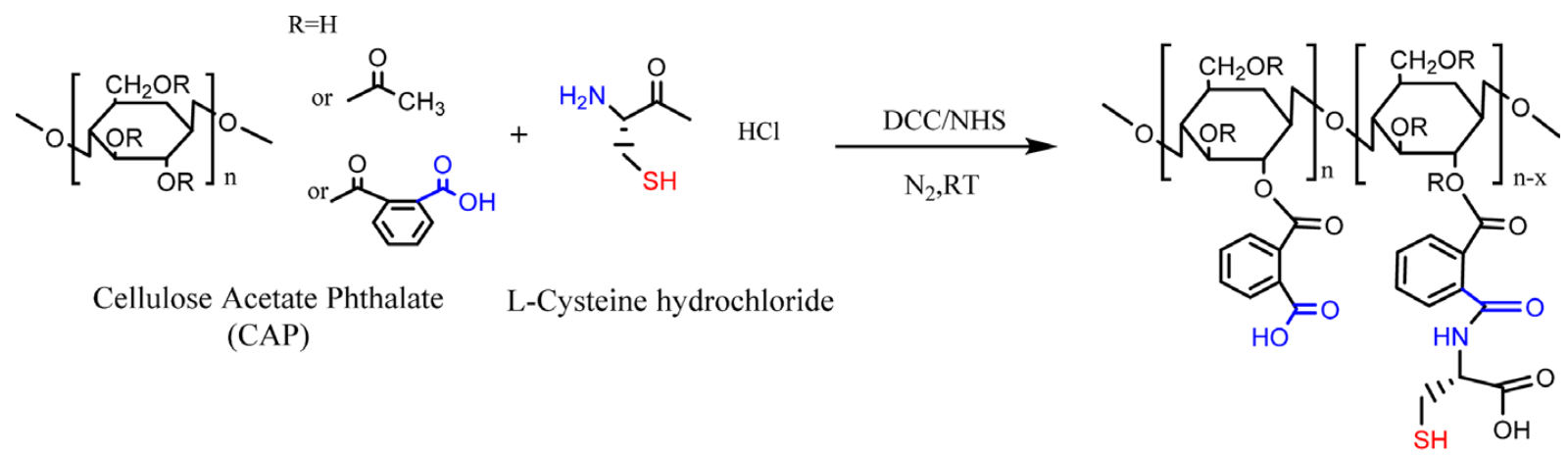

Thiolated CAP

Figure 5. Synthesis scheme of thiolated cellulose acetate phthalate (T-CAP).$^{42}$ Copyright 2018, with permission from Springer. 
therefore elicited sufficient antibody levels and neutralizing effect after oral administration.

\subsection{Synthetic polymer-based system}

Eudragits ${ }^{\circledR}$ are mostly copolymers of acrylic and methacrylic acid ester, of which the physicochemical properties are determined mainly by their functional groups. Eudragits ${ }^{\circledR}$ have advantages of $\mathrm{pH}$-dependent release profiles, high package rate, controlrelease of the incorporated drug, and high stability. ${ }^{67}$ Therefore, the main purpose of Eudragit ${ }^{\circledR}$ was to develop a single coating layer for prevention the drug release at low $\mathrm{pH}$ environment and slowing down the drug release in the target site, ${ }^{68}$ commonly utilized in the formulation of $\mathrm{pH}$-sensitive drug molecules. ${ }^{69}$

Eudragit ${ }^{\circledR}$ RS100 (RS) and RL100 (RL) as a main application in non-steroidal anti-inflammatory drugs, have been proposed as ocular delivery systems with prolonged release and improved ocular availability, which showed good properties of stability and size distribution and positive surface charge. ${ }^{70} \mathrm{RL}$, totally esterified with no free carboxylic acid group, is neutral in character and insoluble in the entire physiological pH range, can be dissolved in water and can be utilized to improve the impermeability characteristics of poorly permeable biomolecules because variation in the quantity of quaternary ammonium group makes variation in permeability. On the other hand, RS composed of methacrylic acid and methyl methacrylate (1:2, $M_{w}=$ approx. $135,000)$, was also chosen as a $\mathrm{pH}$-sensitive polymer owing to its unique dissolution behavior above $\mathrm{pH}$ 7.0.

Oral vaccine, which is expected to be a possible method of mass vaccination, not only is convenient, but also decrease the cost for vaccine administration. Cho et $a l^{71}$ developed an oral protein drug delivery system using Eudragit-cysteine-coated chitosan microspheres (TECMs). They used bovine serum albumin (BSA) as a protein model drug and BSA-loaded TECMs were prepared by coating negative charged thiolated Eudragit with BSA-loaded positive charged chitosan microspheres (CMs) to study the release character of the delivery system. It was found that the BSA from BSA-loaded TECMs was sustainably released for several hours at $\mathrm{pH}$ 7.4 PBS solution, whereas the release rate was observably suppressed at $\mathrm{pH}$ 2.0 PBS solution. BSA released from BSA-loaded TECMs maintained structural integrity guaranteed by circular dichroism (CD) spectroscopy. The mucoadhesive property of TECMs was significantly higher than that of Eudragit-coated chitosan microspheres (ECMs) and CMs both in vitro and in vivo. The percentage of TECMs remained on the isolated porcine intestinal mucosa surface was significantly higher than those of CMs and ECMs, indicating that TECMs had comparatively stronger mucoadhesive characters. Therefore, TECMs have potentials to be an oral protein drug carrier. Similarly, Shastrl et al. have detailed the development two different microparticulate formulations with varying release profiles for oral influenza vaccines to study the difference of evaluation. Briefly, oral influenza vaccine formulations using inactivated influenza virus as an antigen and enteric-coated Eudragit microparticles as a delivery tool, which kept the antigen efficiently at lower $\mathrm{pH}$, and resulted in vaccine stability, suggestion of playing a role of effective protection. ${ }^{72}$
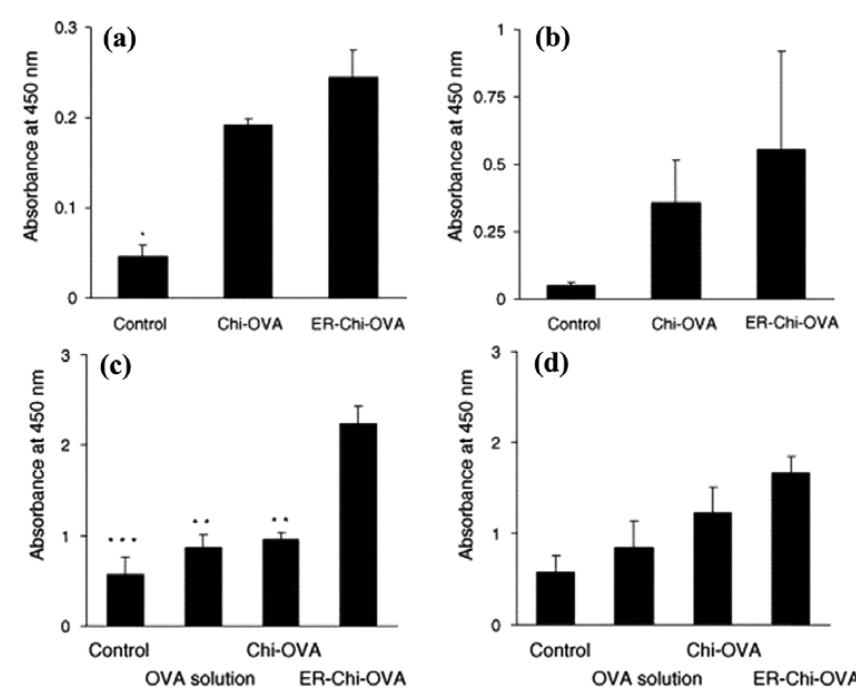

Figure 6. Plasma OVA-specific IgG responses induced by oral administration of several samples at (a) $200 \mu \mathrm{g}$ OVA/mouse and (b) $800 \mu \mathrm{g}$ OVA/mouse; Fecal OVA-specific IgA responses induced by oral administration of several samples at (c) $200 \mu \mathrm{g} \mathrm{OVA} /$ mouse and (d) $800 \mu \mathrm{g}$ OVA/mouse. ${ }^{73}$ Copyright 2005, with permission from Elsevier.

Hori et al. produced RL-coated chitosan (Chi) microparticles containing ovalbumin (OVA) by both ionic gelation and emulsification-solvent evaporation method. At the same time of measuring OVA-specific antibodies, there were the high induction of OVA-specific IgG in plasma and OVA-specific IgA in fecal (Figure 6), suggesting that RL-Chi-OVA can be useful to induce an intestinal mucosal immune response. ${ }^{73}$

\section{4. pH-sensitive and mucoadhesive polymers with cell specificity}

\subsection{Targeting to antigen presenting cells (APCs)}

For an effective delivery of vaccine via nasal route, one major limitation of rapid mucosal clearance of vaccine in nasal epithelium can be overcome by mucoadhesive polymeric carriers, because the mucoadhesive carries can retain sufficient delivery of vaccine from the carriers for a longer duration through the NALT. ${ }^{74}$ However, another limitation of the weak immune response induced owing to inefficient antigen presentation by APCs should be solved. Li et $a l^{75}$ decorated $\mathrm{pH}$-sensitive and mucoadhesive thiolated Eudragit L-100 (TE) by a mannan as a specific ligand to mannose receptors (MR) in APCs to induce efficient immune responses. They confirmed surface decoration of mannan in mannose-decorated TE MPs (Man-TEM) by CLSM, because the mannan also functioned as a stabilizer during preparation of MPs through double emulsion method due to the amphiphilic property of the mannan. They also confirmed the phagocytosis ability of Man-TEM by APCs. Due to the specific interaction between mannan in the Man-TEM and MR of both cells, more internalization of Man-TEM by RAW 264.7 and JAWS II as APCs was observed than that of TEM. Furthermore, mice treated with ovalbumin (OVA)-loaded Man-TEM in the bronchoalveolar lavage, nasal wash, vaginal wash and intestinal wash after nasal vaccination showed higher titers of anti- 

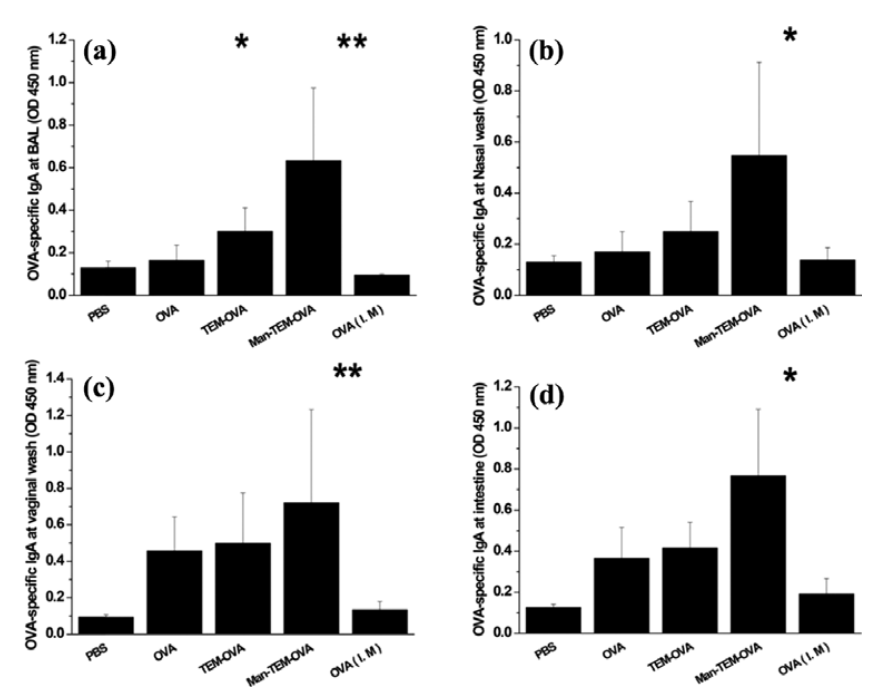

Figure 7. OVA-specific IgA performance in mucosal site at 6 weeks postimmunization. OVA-specific bronchoalveolar lavage (a), nasal wash (b), vaginal wash (c), and intestinal wash (d) IgA levels in mice immunized with each indicated formulations were analyzed by ELISA and then calculated as optical density $(450 \mathrm{~nm})(\mathrm{n}=5$, error bar represents standard deviation; *p b 0.1, ** p b 0.05 , *** p b 0.01 , one-way ANOVA).${ }^{75}$ Copyright 2015, with permission from Elsevier.

OVA IgA antibody responses compared with the another groups as shown in Figure 7, because the Man-TEM increased the uptake of vaccine via the respiratory epithelium owing to the prolonged residence of vaccines by the mucoadhesive property of TE and mannan in Man-TEM increased uptake of vaccines owing to the MR in APCs. ${ }^{71}$ Similarly, Li et al. ${ }^{76}$ prepared $\mathrm{pH}-$ responsive PLGA surface-modified with chitosan for the mucoadhesive property, and mannan for targeting APCs to deliver hepatitis B surface antigen (HBsAg) through nasal route after encapsulation of $\mathrm{NaHCO}_{3}$ to exhibit $\mathrm{pH}$-sensitivity of prepared MPs. The results indicated that mannan- and chitosan-coated pH-sensitive PLGA MPs induced stronger humoral and immune responses compared with other groups. Recently, Li et al. ${ }^{77}$

(a)

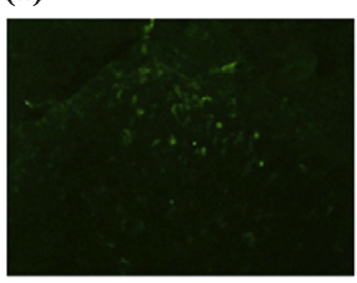

Alexa 488

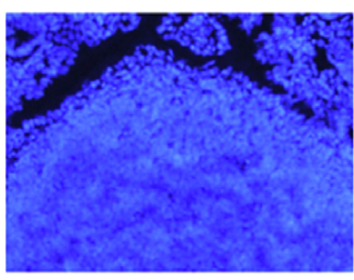

DAPI

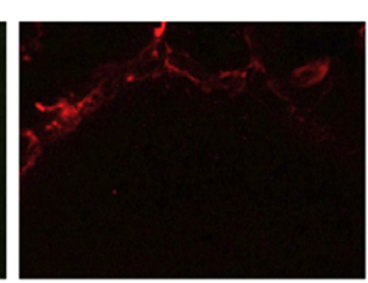

UEA-1

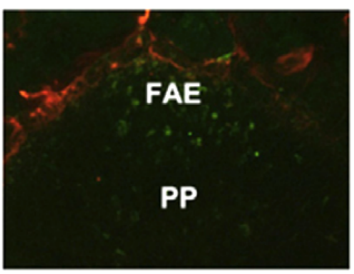

Merge
DAPI
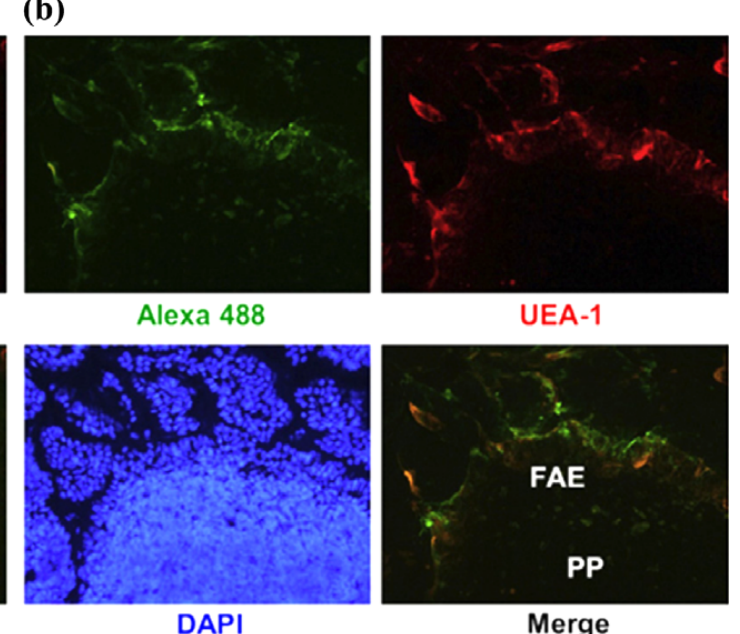

decorated another $\mathrm{pH}$-sensitive and mucoadhesive thiolated HPMCP (THPMCP) by mannan for targeting MR of APCs in the respiratory immune system. It was found that $0.5 \mathrm{wt} \%$ of mannan was coated in THPMCPs during the preparation of MPs by double emulsion due to the function of stabilizer. When cellular uptake of MPs by RAW264.7 was performed by FACS, ManTHPMCPs showed significantly higher uptake efficiency in RAW264.7 cells at $1 \mathrm{~h}$ post-treatment than THPMCPs as shown in Figure 7, although there were no significant differences between THPMCPs and Man-THPMCPs at $2 \mathrm{~h}$ due to the non-specific uptake ability of the RAW264.7 cells. Also, in vivo optical imaging showed that Cy5.5-OVA-loaded THPMCPs and Cy5.5-OVAloaded Man-THPMCPs were retained in the lung at $4 \mathrm{~h}$ after nasal administration whereas the majority of free Cy5.5-OVA disappeared within $1 \mathrm{~h}$. Furthermore, ApxIIA subunit vaccine (vaccine of porcine pleuropneumoniae pathogen)-loaded ManTHPMCPs showed higher levels of mucosal IgA and serum IgG than ApxII or ApxII-loaded THPMCPs owing to the specific interaction between the mannose in the Man-THPMCPs and the MR of the APCs, suggesting that mucoadhesive Man-THPMCPs can be a promising carrier for a nasal vaccine delivery to induce mucosal and systemic immunity.

\subsection{Targeting to $M$ cells}

The M cells located on the follicle-associated epithelium (FAE) in the PP follicles uptake and deliver antigens from the enteric environment into the PP follicles through the transcytosis. ${ }^{78}$ The antigens delivered via M cells induce antigen-specific immune response through activation of APCs and lymphocytes located on the PP follicles. ${ }^{79,80}$ Therefore, it is very important to target the $\mathrm{M}$ cells for efficient mucosal vaccination. Yoo et $a l^{78}$ identified an M cell-homing peptide ligand, CKSTHPLSC (abbreviated as CKS9), via phage display screening technique and confirmed specific localization of CKS9-conjugated chitosan nanoparticles to the FIAE of PP in mice as shown in Figure 8.

Oral vaccine delivery has several advantages for efficient

(b)

Figure 8. In vivo localization of fluorescent CKS9-immobilized chitosan nanoparticles (CKS9-CNs) compared with chitosan nanoparticles (CNs) on the rat Peyer's patch region at $1 \mathrm{~h}$ after injection into closed ileal loops; (a) CNs-Alexa 488, (b) CKS9-CNs-Alexa 488. Green and red fluorescent signals in each panel indicate the location of the chitosan nanoparticles and follicle-associated epithelium (FAE) of PP in rat small intestinal tissues, respectively. ${ }^{78}$ Copyright 2010, with permission from Elsevier. 
induction of mucosal immunization ${ }^{81}$ although there are two limitations such as degradation of the vaccine in the gastrointestinal (GI) tract owing to the low pH and enzymes in the stomach, and rapid mucosal clearance of vaccine in the FIAE. Also, the vaccine should reach $M$ cells to stimulate adequate immune responses after oral delivery, although degradation of vaccine and rapid mucosal clearance of vaccine can be overcome using $\mathrm{pH}$-sensitive and mucoadhesive polymer, respectively. Jiang et $a l^{82}$ checked the targeting ability of coumarin-6-loaded PLGA MPs coated with CKS9-conjugated chitosan after injection into the closed ileal loops of mice. The results indicated that the colocalization of the coumarin-6-loaded CKS9-conjugated chitosan-coated PLGA MPs was much more in the PP region than coumarin-6-loaded PLGA MPs due to the introduction of M cell targeting peptide. Also, oral immunization of membrane protein B of Brachyspira hyodysenteriae (BmpB)-loaded PLGA NPs coated with CKS9-conjugated chitosan showed high secretory IgA responses in the mucosal tissues and systemic IgG responses with induction of Th1- and Th2-type in mice. On the other hand, Singh et $a l^{83}$ prepared M cell targeting peptide$\mathrm{BmpB}$ protein (M-BmpB) as a subunit vaccine of Brachyspira hyodysenteriae against gastrointestinal pathogen in pigs through an insertion of $\mathrm{M}$ cell targeting peptide and $\mathrm{BmpB}$ genes into pET21a expressing vector in E. coli to have specificity of vaccine towards $\mathrm{M}$ cells instead of $\mathrm{M}$ cell targeting peptide-conjugated vaccine carrier because uptake of orally delivered antigens through M cells is very low due to lack of specificity of antigens towards $\mathrm{M}$ cells. When they compared uptake of antigens through M cells between M-BmpB/THPMCP and M-BmpB/HPMCPs MPs after administration of MPs to mice by oral gavage, more antigens entered into the GALT by the M-BmpB/THPMCP MPs than M-BmpB/HPMCP MP due to synergistic effect of M cell targeting ligand and mucoadhesive of the antigen carrier. Also, after immunization with M-BmpB/THPMCP MPs to mice by oral gavage, they induced higher fecal IgA, serum IgG, serum IgG1 and serum IgG2a than M-BmpB/HPMCP MPs or M-BmpB alone (Figure 9), the suggestion of efficient humoral and cell-mediated immune responses by the M-BmpB/THPMCP MPs. Similarly, they synthesized $\mathrm{pH}$-sensitive and mucoadhesive Eudragit L-100 by a reaction of cysteine to deliver $\mathrm{M}-\mathrm{BmpB}$ as an oral vaccine and to investigate the efficacy of the vaccine carrier to induce both mucosal and cellular immunity. ${ }^{84}$ When the mucoadhesive property of the MPs was evaluated by ileal loop assay in mouse intestine, immunohistochemical analysis of the small intestine of mouse showed that the number of thiolated Eudragit (TE) MPs adhered to the intestine was much more than the EMPs. Also, when the ability of antigens with or without M cell homing peptide to the $\mathrm{M}$ cells by the ileal loop assay in mouse intestine ex vivo, the green fluorescence signals of FITC-labeled M$\mathrm{BmpB}$ on the FIAE and PP regions were higher than BmpB due to the specific interaction of $\mathrm{M}$ cell homing peptide with $\mathrm{M}$ cell in FAE. Furthermore, the oral delivery of M-BmpB-TEMPs showed
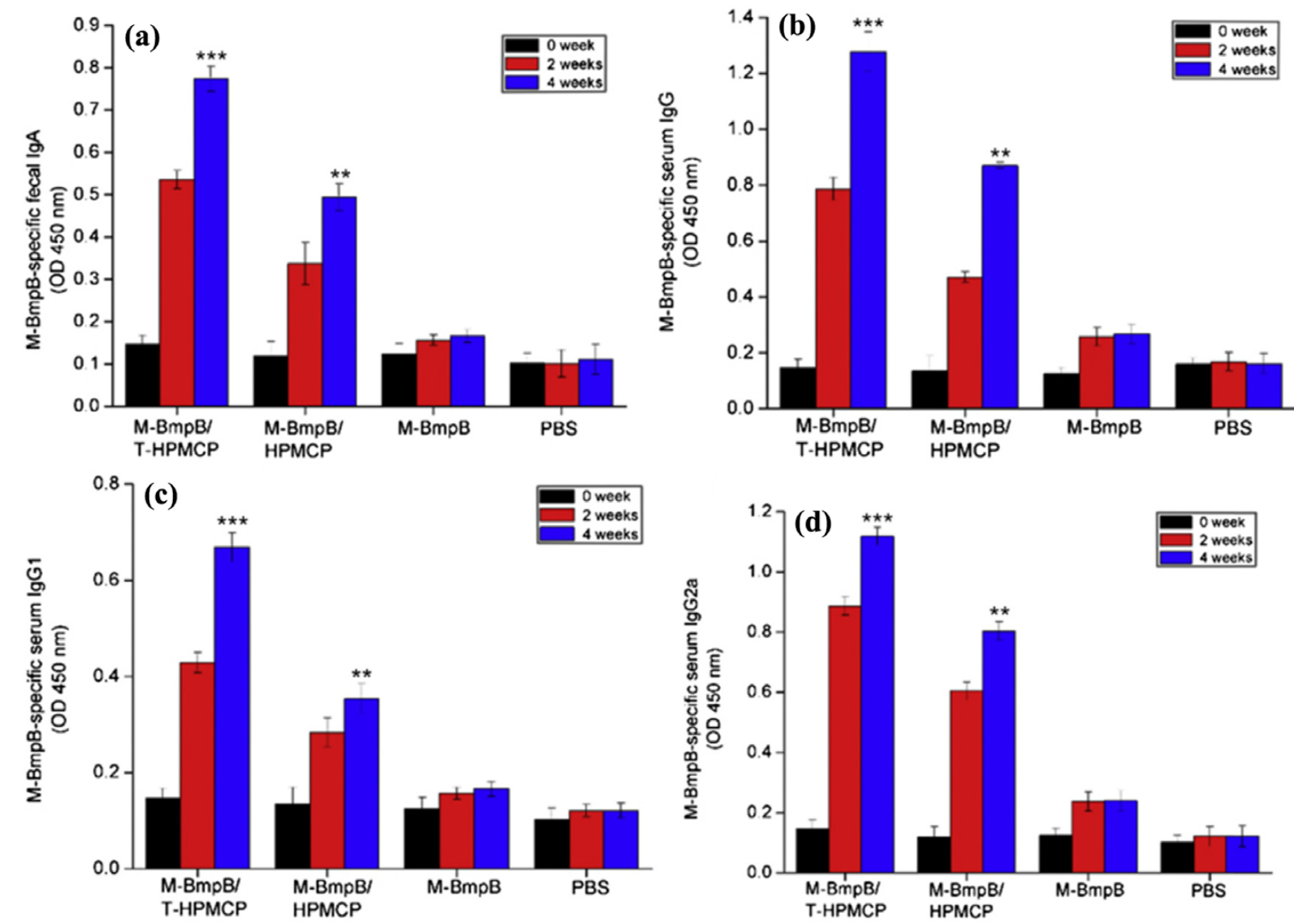

Figure 9. Antigen-specific immune response after oral immunization with MPs. To determine the immune responses, serum and fecal samples were taken from mice at 0,2 , and 5 weeks according to experimental design. Antibody levels were analyzed by ELISA. (a) Anti-M-BmpB IgA levels in feces, (b) Anti-M-BmpB IgG levels in serum, (c) Anti-M-BmpB IgG1 levels in serum, and (d) Anti-M-BmpB IgG2a levels in serum. Statistical significance is compared with M-BmpB only control $\left({ }^{*} P<0.05,{ }^{* *} P<0.01\right.$, and $\left.{ }^{* * *} P<0.001\right)$. ${ }^{83}$ Copyright 2015 , with permission from Elsevier. 
higher BmpB-specific secretory IgA (sIgA), BmpB-specific sIgG and both IgG1 and IgG2a antibody responses than BmpBTEMPs, M-BmpB-EMPs, BmpB and PBS alone at 4 weeks after first immunization, a suggestion of providing a combinatorial method for efficient M-cell-targeted mucosal vaccines.

Interestingly, Taylor et $a{ }^{85}$ reported that receptor activator of nuclear factor- $\kappa \mathrm{B}$ ligand (RANKL) produced by the subepithelial stromal cells beneath the FIAE is a very important factor to stimulate the differentiation of RANK-expressing enterocytes into the M cells. Based on the above-mentioned concept, Maharjan et $a l^{86}$ applied the concept for enhancing oral vaccine efficacy by synchronous induction of $M$ cells and immune cells by systemic administration of full-length transmembrane RANKL (mRANKL), and followed by delivery of M-BmpB using THPMCPs. The results indicated that the number of M cell-specific anti-glycoprotein 2 (GP2) as a specific surface marker for mature $\mathrm{M}$ cells ${ }^{87}$ in the FAE of mRANKL recipient mice was significantly increased over other groups. Also, uptake of antigens into the PPs of RANKL-treated mice after treatment of FITClabeled BmpB-laoaded THPMCP MPs orally in mice was higher than control. Furthermore, RANKL recipient mice showed significantly higher IgA titer than the PBS recipient group due to the increased number of M cells in PPs by the treatment of RANKL.

\section{Conclusion and perspective}

Mucosal vaccines can induce mucosal and systemic immunity simultaneously. Especially, the particulate vaccines have several advantages for mucosal delivery among the alternative vaccine delivery system. Amounts of evidence have performed the importance of the changes in cell composition, function, and energy metabolism in the host immune responses and the subsequent incidence of inflammatory, allergic, and infectious diseases. Therefore, the individual difference caused by the host is a mucosal immunotherapy to be solved. Besides, it should be pointed out that not all of the rodent models are directly translated into humans due to their great disparities in the diet and symbiotic bacteria. The challenge now is the design of a new type of vaccine to conduct comparative clinical trials for systematically monitoring all parameters of the immune response in serum, local secretions, mucosal tissues-body fluids and cells, and mucous membranes. Much more remains to be done about mucosal immune, but current research is still refining these concepts and developing the potential mucosal vaccines using $\mathrm{pH}$-sensitive and targeting mucoadhesive vaccine carriers.

\section{References}

(1) R. Rappuoli, C. W. Mandl, S. Black, and E. De Gregorio, Nat. Rev. Immunol., 11, 865 (2011).

(2) G. Alter and R. P. Sekaly, Vaccine, 33, B55 (2015).

(3) B. Singh, S. Maharjan, K. H. Cho, L. Cui, I. K. Park, Y. J. Choi, and C. S. Cho, Int. J. Biol. Macromol., 110, 54 (2018).

(4) B. Pulendran, S. Li, and H. I. Nakaya, Immunity, 33, 516 (2010).

(5) K. Hase, K. Kawano, T. Nochi, G. S. Pontes, S. Fukuda, M. Ebisawa, K. Kadokura, T. Tobe, Y. Fujimura, S. Kawano, A. Yabashi, S. Waguri, G. Nakato, S. Kimura, T. Murakami, M. Iimura, K. Hamura, S. Fukuoka, A.
W. Lowe, K. Itoh, H. Kiyono, and H. Ohno, Nature, 462, 226 (2009).

(6) J. Holmgren, C. Czerkinsky, K. Eriksson, and A. Mharandi, Vaccine, 21, S89 (2003).

(7) J.W.Simecka, Adv. Drug Deliv. Rev., 34, 235 (1998).

(8) L. Kaur, A. Sharma, A. K. Yadav, and N. Mishra, Artif. Cells Nanomed. Biotechnol., 7, 1 (2017).

(9) B. Singh, S. Maharjan, T. Jiang, S. K. Kang, Y. J. Choi, and C. S. Cho, Mol. Pharm., 12, 3816 (2015).

(10) M. L. Kang, C. S. Cho, and H. S. Yoo, Biotechnol. Adv., 27, 857 (2009).

(11) F. W. Merkus, J. C. Verhoef, N. G. Schipper, and E. Marttin, Adv. Drug Deliv. Rev., 29, 13 (1998).

(12) M. A. Sarkar, Pharm. Res., 9, 1 (1992).

(13) M. A. Islam, T. E. Park, E. Reesor, K. Cherukula, A. Hasan, J. Firdous, B. Singh, S. K. Kang, Y. J. Choi, I. K. Park, and C. S. Cho, Curr. Pharm. Des., 21, 4285 (2015).

(14) J.E. Vela Ramirez, L. A. Sharpe, and N. A. Peppas, Adv. Drug Deliv. Rev., 114, 116 (2017).

(15) V. Pavot, N. Rochereau, C. Genin, B. Verrier, and S. Paul, Vaccine, 30, 142 (2012).

(16) J. Holmgren and A. M. Svennerholm, Curr. Opin. Immunol, 24, 343 (2012).

(17) T. Pelaseyed, J. H. Bergstrom, J. K. Gustafsson, A. Ermund, G. M. Birchenough, A. Schutte, S. van der Post, F. Svensson, A. M. RodriguezPineiro, E. E. Nystrom, C. Wising, M. E. Johansson, and G. C. Hansson, Immunol. Rev., 260, 8 (2014).

(18) J. Renukuntla, A. D. Vadlapudi, A. Patel, S. H. Boddu, A. K. Mitra, Int. J. Pharm., 447, 75 (2013).

(19) J. Mestecky, M. W. Russell, and C. O. Elson,J. Immunol, 179, 5633 (2007).

(20) B. Wang, in Oral Bioavailability: Basic Principles, Advanced Concepts, and Applications, John Wiley \& Son, Inc., Hoboken, 2011, p 21.

(21) K. Pathak, Int. J. Pharm. Investig., 1, 62 (2011).

(22) R. Shaikh, T. R. Raj Singh, M. J. Garland, A. D. Woolfson, and R. F. Donnelly, J. Pharm Bioallied Sci., 1, 3 (2011).

(23) B. Demirdirek and K. E. Uhrich, Int. J. Pharm., 1-2, 528 (2017).

(24) S. H. S. Leung and J. R. Robinson, J. Control. Release, 5, 223 (1987).

(25) H. Seok, Y. Y. Jo, H. Y. Kweon, S. G. Kim, M. K. Kim, and W. S. Chae, Tissue Eng. Regen. Med., 14, 221 (2017).

(26) S. Somekawa, A. Mahara, K. Masutani, Y. Kimura, H. Urakawa, and T. Yamaoka, Tissue Eng. Regen. Med., 14, 507 (2017).

(27) K. H. Cho, B. Singh, S. Maharjan, Y. Jang, Y. J. Choi, and C. S. Cho, Tissue Eng. Regen. Med., 14, 211 (2017).

(28) S. Bang, U. W. Jung, and I. Noh, Tissue Eng. Regen. Med., 15, 25 (2018).

(29) B. M. Boddupalli, Z. N. K. Mohammed, R. A. Nath, and D. Banji, J. Adv. Pharm. Technol. Res., 1, 381 (2011).

(30) H. B. Lee, S. Y. Yoon, B. Singh, S. H. Oh, L. Cui, C. Yan, S. K. Kang, Y. J. Choi, and C. S. Cho, Tissue Eng. Regen. Med., 15, 1 (2018).

(31) M. A. Suckow, L. Z. Jarvinen, H. HogenEsch, K. Park, and T. L. Bowersock, J. Control. Release, 85, 227 (2002).

(32) M. Chidambaram and K. Krishnasamy, Nano Biomed. Eng., 5, 28 (2013).

(33) S. Chattopadhyay, J. Y. Chen, H. W. Chen, and C. J. Hu, Nanotheranostics, 1, 244 (2017).

(34) A. Farhadian, N. M. Dounighi, and M. Avadi, Hum. Vaccin. Immunother., 11, 2811 (2015).

(35) J. L. Spinner, H. S. Oberoi, Y. M. Yorgensen, D. S. Poirier, D. J. Burkhart, M. Plante, and J. T. Evans, Vaccine, 33, 5845 (2015).

(36) H. L. Jiang, I. K. Park, N. R. Shin, H. S. Yoo, T. Akaike, and C. S. Cho, Arch. Pharm. Res., 27, 346 (2004).

(37) H. L. Jiang, I. K. Park, N. R. Shin, S. G. Kang, H. S. Yoo, S. I. Kim, S. B. Suh, T. Akaike, and C. S. Cho, Eur. J. Pharm. Biopharm., 58, 471 (2004).

(38) H. L. Jiang, M. L. Kang, J.-S. Quan, S. G. Kang, T. Akaike, H. S. Yoo, and C. S. Cho, Biomaterials, 29, 1931 (2008).

(39) S. A. Bucarey, M. Pujol, J. Poblete, I. Nuñez, C. V. Tapia, A. Neira-Carrillo, J. Martinez, and O. Bassa, Virol. J., 11, 1 (2014).

(40) K. Kaur, R. K. Sodhi, A. Katyal, R. Aneja, U. K. Jain, O. P. Katare, and J. 
Madan, Colloid Surf. B., 132, 225 (2015).

(41) H. Chen, V. Torchilin, and R. Langer, Pharm. Res., 13, 1378 (1996).

(42) X. Zheng, Y. Huang, C. Zheng, S. Dong, and W. Liang, AAPS J., 12, 519 (2010).

(43) H. O. Alpar, S. Somavarapu, K. N. Atuah, and V. W. Bramwell, Adv. Drug Deliv. Rev., 57, 411 (2005).

(44) X. Y. Li, X. Y. Kong, S. Shuai, X. L. Zheng, G. Gang, Y. Q. Wei, and Z. Y. Qian, BMC Biotechnol, 8, 89 (2008).

(45) K. Zhao, Y. Zhang, X. Zhang, W. Li, C. Shi, C. Guo, C. Dai, Q. Chen, Z. Jin, Y. Zhao, H. Cui, and Y. Wang, Int. J. Nanomedicine, 9, 389 (2014).

(46) W. Xu, Y. Shen, Z. Jiang, Y. Wang, Y. Chu, and S. Xiong, Vaccine, 22, 3603 (2004).

(47) X. Zhou, B. Liu, X. Yu, X. Zha, X. Zhang, Y. Chen, X. Wang, Y. Jin, Y. Wu, and Y. Chen, J. Control. Release, 121, 200 (2007).

(48) S. Heuking and G. Borchard, J. Pharm. Sci., 101, 1166 (2012).

(49) D. Klemm, B. Heublein, H. P. Fink, and A. Bohn, Angew. Chem., 44, 3358 (2005).

(50) S. Kamel and S. Kamel, Express Polym. Lett., 2, 758 (2008).

(51) I. Maharaj, J. G. Nairn, and J. B. Campbell, J. Pharm. Sci., 73, 39 (1984).

(52) V. Lazzell, R. H. Waldman, C. Rose, R. Khakoo, A. Jacknowitz, and S. Howard, J. Biol. Stand., 13, 315 (1984).

(53) S. Y. Lin, Y. L. Tzan, C. J. Lee, and C. N. Weng, J. Microencapsul., 8, 317 (1991).

(54) S. Y. Lin, Y. L. Tzan, C. N. Weng, and C. J. Lee, J. Microencapsul., 8, 537 (1991).

(55) Y. Song, Y. Zhou, S. van Drunen Littelvan den Hurk, and L. Chen, Biomaterials Sci., 2, 1440 (2014).

(56) H. Wang and M. Roman, Nanomed-Nanotechnol., 12, 489 (2016).

(57) M. M. Pieler, S. Frentzel, D. Bruder, M. W. Wolff, and U. Reichl, Vaccine, 34, 6367 (2016).

(58) M. Tafaghodi, S. A. Sajaditabasi, and M. R. Jaafari, J. Biomater. SciPolym. E, 17, 909 (2006).

(59) M. Tafaghodi and M. Eskandari, Iran. J. Basic Med. Sci., 15, 873 (2012).

(60) D. O'Hagan and A. Pavesio, U. S. Patent 794730982 (2011).

(61) Y. Fan, P. Sahdev, L. J. Ochyl, J. Akerberg, and J. J. Moon, J. Control. Release, 208, 121 (2015).

(62) J. Wojtasz, J. Carlstedt, P. Fyhr, and V. Kocherbitov, Carbohydr. Polym., 135, 225 (2016)

(63) P. Edman, E. Björk, and L. Rydén, J. Control. Release, 21, 165 (1992).

(64) C. Elvira, J. F. Mano, R. J. San, and R. L. Reis, Biomaterials, 23, 1955 (2002).

(65) L. Illum, N. F. Farraj, S. S. Davis, B. R. Johansen, and D. T. O'Hagan, Int. J.
Pharm., 63, 207 (1990)

(66) C. Sturesson and W. L. Degling, J. Control. Release, 68, 441 (2000).

(67) K. L. Deore, N. A. Thombre, and P. S. Gide,J. Pharm. Res., 6, 158 (2013).

(68) M. Rohit, C. Anuj, S. Pooja, and P. Pravin, J. Adv. Pharm.Technol. Res., 4, 31 (2013).

(69) F. C. Kenechukwu and M. A. Momoh, Int. J. Pharm. Investig., 6, 69 (2016).

(70) K. Dillen, J. Vandervoort, G. Van den Mooter, and A. Ludwig, Int. J. Pharm., 314, 72 (2006).

(71) J. S. Quan, H. L. Jiang, E. M. Kim, H. J. Jeong, Y. J. Choi, D. D. Guo, M. K. Yoo, H. G. Lee, and C. S. Cho, Int. J. Pharm., 359, 205 (2008).

(72) P. N. Shastri, M. C. Kim, F. S. Quan, M. J. D'Souza, and S. M. Kang, J. Pharm. Sci., 101, 3623 (2012).

(73) M. Hori, H. Onishi, and Y. Machida, Int. J. Pharm., 297, 223 (2005).

(74) K. Zhao, Y. Zhang, X. Zhang, W. Li, C. Shi, C. Guo, C. Dai, Q. Chen, Z. Jin, and Y. Zhao, PLoS One, 7, e53314 (2012).

(75) H. S. Li, B. Singh, T. E. Park, Z. S. Hong, S. K. Kang, C. S. Cho, and Y. J. Choi, Eur. J. Pharm. Sci, 80, 16 (2015).

(76) Z. Li, F. Xiong, J. He, X. Dai, and G. Wang, Eur.J. Pharm. Biopharm., 109, 24 (2016).

(77) H. S. Li, M. K. Shin, B. Singh, S. Marharjan, T. E. Park, S. K. Kang, H. S. Yoo, Z. S. Hong, C. S. Cho, and Y. J. Choi, J. Control. Release, 233, 114 (2016).

(78) M. K. Yoo, S. K. Kang, J. H. Choi, I. K. Park, H. S. Na, H. C. Lee, E. B. Kim, N. K. Lee, J. W. Nah, and Y. J. Choi, Biomaterials, 31, 7738 (2010).

(79) M. A. Jepson and M. A. Clark, Trends Microbiol., 6, 359 (1998).

(80) P. J. Sansonetti and A. Phalipon, Semin. Immunol., 11, 193 (1999).

(81) M. A. Islam, J. Firdous, Y. J. Choi, C. H. Yun, and C. S. Cho, Int. J. Nanomedicine, 7, 6077 (2012).

(82) T. Jiang, B. Singh, H. S. Li, Y. K. Kim, S. K. Kang, J. W. Nah, Y. J. Choi, and C. S. Cho, Biomaterials, 35, 2365 (2014).

(83) B. Singh, S. Maharjan, T. Jiang, S. K. Kang, Y. J. Choi, and C. S. Cho, Biomaterials, 59, 144 (2015).

(84) B. Singh, S. Maharjan, J. Tao, S. K. Kang, Y. J. Choi, and C. S. Cho, Mol. Pharm., 12, 310 (2015).

(85) R. T. Taylor, S. R. Patel, E. Lin, B. R. Butler, J. G. Lake, R. D. Newberry, and I. R. Williams, J. Immunol., 178, 5659 (2007).

(86) S. Maharjan, B. Singh, T. Jiang, S. Y. Yoon, H. S. Li, G. Kim, M. J. Gu, S. J. Kim, O. J. Park, and S. H. Han, Biomaterials, 84, 286 (2016).

(87) K. Hase, K. Kawano, T. Nochi, G. S. Pontes, S. Fukuda, M. Ebisawa, K. Kadokura, T. Tobe, Y. Fujimura, and S. Kawano, Nature, 462, 226 (2009). 